\title{
Avaliação das complicações pós-colangiopancreatografia endoscópica retrógrada (CPER) em um serviço de endoscopia
}

\author{
Acadêmicos: Edson Francisco Blefari Junior \\ Orientador: André Luis Montagnini
}

Introdução: A CPER é o procedimento invasivo no qual o endoscopista injeta contraste radiopaco pela papila duodenal, sob exame radioscópico e avalia a anatomia das vias biliares e dos canais pancreáticos. As possibilidades terapêuticas deste procedimento incluem desde a remoção de cálculos, realização de biópsias até a drenagem biliar paliativa com próteses plásticas ou metálicas expansíveis (Ferreira, 2013). A maior preocupação com relação à CPER é o desenvolvimento de pancreatite aguda que é a complicação mais comum deste procedimento. A incidência da pancreatite aguda pós CPER varia de 1,6-5,4\% quando relacionada ao procedimento diagnóstico e 1,6-5,4\% quando relacionada ao procedimento terapêutico e a mortalidade relatada desta complicação oscila ao redor de $0,007 \%$ e $0,02 \%$ quando associada somente ao procedimento terapêutico (Arata et al., 2010). A prevenção da pancreatite aguda pós-CPER é um desafio desde que a CPER foi introduzida como um procedimento na década de 70. Além da pancreatite pós-CPER, a hemorragia, perfuração de estruturas adjacentes referentes ao TGI, colangite, colecistite e complicações cardiopulmonares também fazem parte do rol de complicações pós-CPER.

Objetivo: Investigar a frequência de pancreatite aguda pós-CPER em serviço de endoscopia de um hospital de grande porte; Avaliar a gravidade e o impacto desta complicação na evolução dos pacientes; Identificar possíveis fatores de risco para a ocorrência desta complicação.

Método: Pesquisa quantitativa descritiva por meio de levantamento de dados de prontuários de pacientes submetidos à CPER entre os anos de 2011 a 2012 tendo como objeto de estudo as complicações pós-CPER.

Resultados: A amostra foi composta por 102 prontuários de pacientes submetidos à CPER. A frequência de complicações pós-CPER foi 15 (14,3\%), sendo a pancreatite pós-CPER 6 (5,9\%), hemorragia 2 (2,0\%) e colangite 1 (1,0\%). A média de idade da amostra foi 65,33 anos, mas, naqueles com pancreatite pós-CPER, foi 68,50 anos. Destacou-se como justificativa para a realização de CPER a coledocolitíase presente em 41 (40,20\%), obstrução biliar em 31 (30,39\%), colangite em 26 $(25,49 \%)$ e pancreatite aguda em $13(12,75 \%)$. Na admissão hospitalar as principais manifestações clínicas apresentadas foram: dor abdominal em 44 (57,89\%) dos pacientes, icterícia $18(23,68 \%)$, febre $12(15,79 \%)$ e vômitos 9 (11,84\%). Na história pregressa 42 (48,84\%) tinham HAS e 21 (24,42\%) apresentavam cirurgia prévia do TGI. A papilotomia foi o procedimento mais realizado em $73(97,33 \%)$ seguida pela colocação de prótese em 19 (24,1\%) dos pacientes.

Tabela 1 - Complicações pós-CPRE. $(\mathrm{N}=102)$

\begin{tabular}{lcc}
\hline \multicolumn{1}{c}{ COMPLICAÇÃO PÓS-CPER } & N & \% \\
\hline Sem Complicações & 86 & $84,3 \%$ \\
Pancreatite & 6 & $5,9 \%$ \\
Hemorragia & 2 & $2,0 \%$ \\
Colangite & 1 & $1,0 \%$ \\
\hline
\end{tabular}

Discussão e Conclusão: A pancreatite pós-CPER foi a complicação mais frequente e todos os pacientes que desenvolveram pancreatite pós-CPER eram do sexo feminino, não eram tabagistas, nem etilistas e tiveram uma média de dias de internação hospitalar de 16,2 dias. Destas, 02 (33,3\%) possuíam cirurgia prévia do TGI. Houve um total de 03 óbitos nos pacientes que apresentaram complicação pós-CPER, sendo $01(33,3 \%)$ relacionado à pancreatite pós CPER. Tal fato permite-nos afirmar que a pancreatite aguda foi responsável por 33,3\% dos óbitos dos pacientes com complicações pós-CPER.

Referências

Arata S, et al. Post-ERCP pancreatitis. J Hepato-Biliary-Pancreatic Sci. (Tokyo). 2010;17:70-8.

Ferreira F. Colangiopancreatografia. In: Averbach M. Endoscopia digestiva - diagnóstico e tratamento. Rio de Janeiro: Revinter; 2013. Cap.21. 